\title{
Anorectal Manometry on Children: A Moroccan Series and Literature Review
}

\author{
Hanane Delsa ${ }^{1,2 *}$ (D) Ilham Serraj ${ }^{1}$, Mohamed Khalis ${ }^{3}$, Nawal Kabbaj ${ }^{1}$ \\ ${ }^{1}$ EFD-Hepatogastroenterology Unit, Ibn Sina Hospital, Rabat, Morocco; ${ }^{2}$ Department of Gastroenterology, Faculty of Medicine, \\ Mohammed VI University of Health Sciences (UM6SS), Casablanca, Morocco; ${ }^{3}$ Department of Epidemiology, International \\ School of Public Health, Mohammed VI University of Health Sciences (UM6SS), Casablanca, Morocco
}

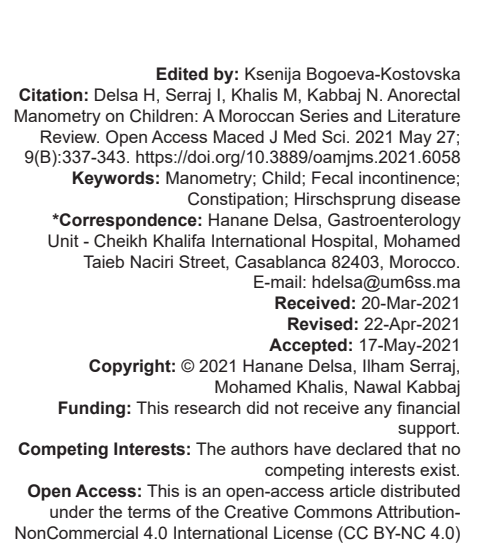

Abstract

BACKGROUND: Anorectal manometry (ARM) is a test used to evaluate the rectum and anus functions. It also helps to diagnose several conditions such as fecal incontinence and constipation. This test is being increasingly performed on children of all ages.

AIM: The aim of our study is to determine the benefit of ARM on children and to report our experience.

METHODS: Over a period of 4 years, data and test results of 273 children were analyzed

RESULTS: Out of 273 patients ( $68.5 \%$ boys and $31.5 \%$ girls with a mean age of 9 years), 154 patients (51.6\%) had fecal incontinence (Group 1), 75 children (27.5\%) had chronic constipation (CC) (Group 2), and 37 children $(13.6 \%)$ had both of them (Group 3). An awake manometry was performed on 248 children (91\%); however, under sedation, the test allowed us the exclusion of Hirschsprung's disease (HD) in 21 children (84\%). Bad anal contraction was present in $25 \%$ of patients in group 1 and $21.6 \%$ of patients in group 3 . The statistical analysis showed a significant difference in age $(p=0.022)$ and resting pressure $(p=0.050)$ between the three groups. Children with fecal incontinence had a higher rate of dyssynergy, $80.2 \%$ and $83.8 \%$, in groups 1 and 3 , respectively, compared to $60.4 \%$ in patients with CC $(p=0.852)$

CONCLUSION: ARM is the gold standard for terminal constipation and encopresis exploration on children. In our study, this test was efficient for the exclusion of HD in infants suffering from constipation, in the other hand, we found a high rate of dyssynergy on children with fecal incontinence $(80 \%)$ and a biofeedback therapy was proposed in this case.

\section{Introduction}

Anorectal manometry (ARM) is a diagnostic test used to evaluate the rectum and anus functions. For more than a century, it was the exploration of choice for adults suffering from chronic constipation (CC) resistant to conservative treatments (diet, laxatives, toileting regime), and for defecation disorders diagnosis including evacuation difficulties (dyssynergic defecation) and fecal incontinence (FI) [1], it was also used to study anorectal function before or after bowel surgery.

On children presenting the same symptoms, ARM was not commonly used as part of routine investigations.

Finally, this test is increasingly used on children of all ages, particularly for the screening of Hirschsprung's disease (HD), the most important indication for ARM in pediatric population. This test can be performed awake, under general anesthesia (GA), or under sedation.

Little data are available on ARM on children in the literature, the knowledge of normal values is very limited even for the protocol used. More studies are needed for better comprehension and standardization of data on children.

In Morocco, our unit was the first to perform ARM on children. The objective of this study was to determine the benefit of ARM on children, the modalities, stages, and especially it is particularities on this population, as well as to report a Moroccan experience. To the best of our knowledge, this study is the first in our country to prove the benefit of ARM on children.

\section{Methods}

A retrospective, observational, and analytic study was conducted over a period of 4 years. All children referred for ARM to the EFD-Hepatogastroenterology unit, Ibn Sina Hospital, Rabat, Morocco, were included in the study.

An informed consent/assent of the parents and underage children was obtained before the procedure. 
A traditional ARM was performed on all patients, a sedation was needed in some cases where the children were too young, not sufficiently cooperative, or the procedure was excessively invasive.

The measurements were taken on patients in left lateral decubitus position after rectal cleansing by enema. The sterile probe (MMS) has a balloon. Data acquisition, online visualization, and signal processing were performed using a commercially available manometric system (Figure 1: 1-manometry catheters, 2-pressure sensors, 3-recording equipment).

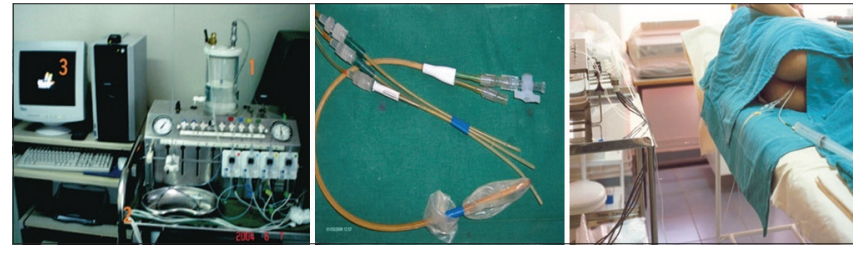

Figure 1: The material of the anorectal manometry of our unit

\section{How to perform the ARM}

Before the procedure, a rectum examination is performed by the operator.

Through the anus, we place a catheter with a balloon into the rectum. This balloon will be progressively inflated, the sensors allow the measurement of pressures and sensations. In general, this procedure lasts between 15 and $30 \mathrm{~min}$, in this time, the patient is required to do many maneuvers such as cough, squeeze, and push the balloon out.

An enema must be taken at home before the exam. The nurse must provide the patient with all the explanations about the enema (type, quantity). If sedation is needed, the patient must fast, otherwise, he can drink and eat normally before the test.

The catheters in a conventional ARM have fewer sensors (3-6 unidirectional sensors) with wider intervals between them; a pull-through technique is needed to allow precise position of the anal sphincter. Consequently, the time of the test will be longer compared with stationary techniques used in HRAM. However, the catheters of the conventional manometry are robust, durable, and less expensive.

The HRAM has several densely positioned sensors (up to 36) circumferentially across a defined length of the catheter that allows us to have a topographic color contour or line plot. These catheters have the advantage to be used as a stationary examination which can reduce the duration of the test, but they are fragile and expensive.

On adults, HRAM compared with conventional ARM is significantly more expensive and superior. On children, few studies were performed to compare these two techniques [1].

To perform ARM, we use many maneuvers following steps in a sequence which were described by the British Society of Paediatric Gastroenterology, Hepatology and Nutrition (BSPGHAN) motility group, between each maneuver, there are $30 \mathrm{~s}$ of recovery (Figure 2) [1], [2].

For adults, several maneuvers are performed. For suspicion of dyssynergic defecation, the balloon expulsion test is an important step. It is a balloon measuring $4 \mathrm{~cm}$ that will be placed in the rectum and filled with warm water $(50 \mathrm{ml})$. After placement of the balloon, the patient must expel it.

The balloon expulsion time is calculated with a stopwatch, normally it is estimated to $1 \mathrm{~min}$ [3]. However, it depends on body position and types of balloons [3], [4]. For dyssynergic defecation, this time is very useful with high specificity (80-90\%) but low sensitivity $50 \%$ [5].

Resting pressure (RP), maximum pressure, presence or absence of rectoanal inhibitory reflex (RAIR), and dyssynergy were consecutively evaluated. Afterward, the balloon was manually insufflated to measure the first sensation, the urge to defecate, and the maximum tolerance of pain.

Once the test is completed, the tube is removed and the patient can go home and resume his normal activity.

\section{Interpretation of the ARM}

There are many challenges using conventional ARM or HRAM on children. The main one is the technical standardization and the establishment of new normative data sets for recognizing the measures of anal sphincter function so that solutions can be transferable between institutions, a problem that has bedeviled traditional practice [1].

Since there are no standardized normal values on children, the BSPGHAN motility group propose to use adults values for kids $<12$ years old and consider the values proposed by Banasiuk et al. because he is the one that published the largest pediatric series of children without lower gastrointestinal symptoms (Table 1) [6].

This group also proposes parameters interpretation to each indication of ARM/HRAM (Table 2) [1], [5], [7].

\section{Statistical analysis}

Data analysis was performed using SPSS (IBM version 20) software. Means \pm standard deviations were presented for continuous variables, frequencies and percentages were presented for qualitative variables. Continuous variables were compared with the use of the Student's t-test or Mann-Whitney test, when appropriate. The Chi-square test was used to compare 


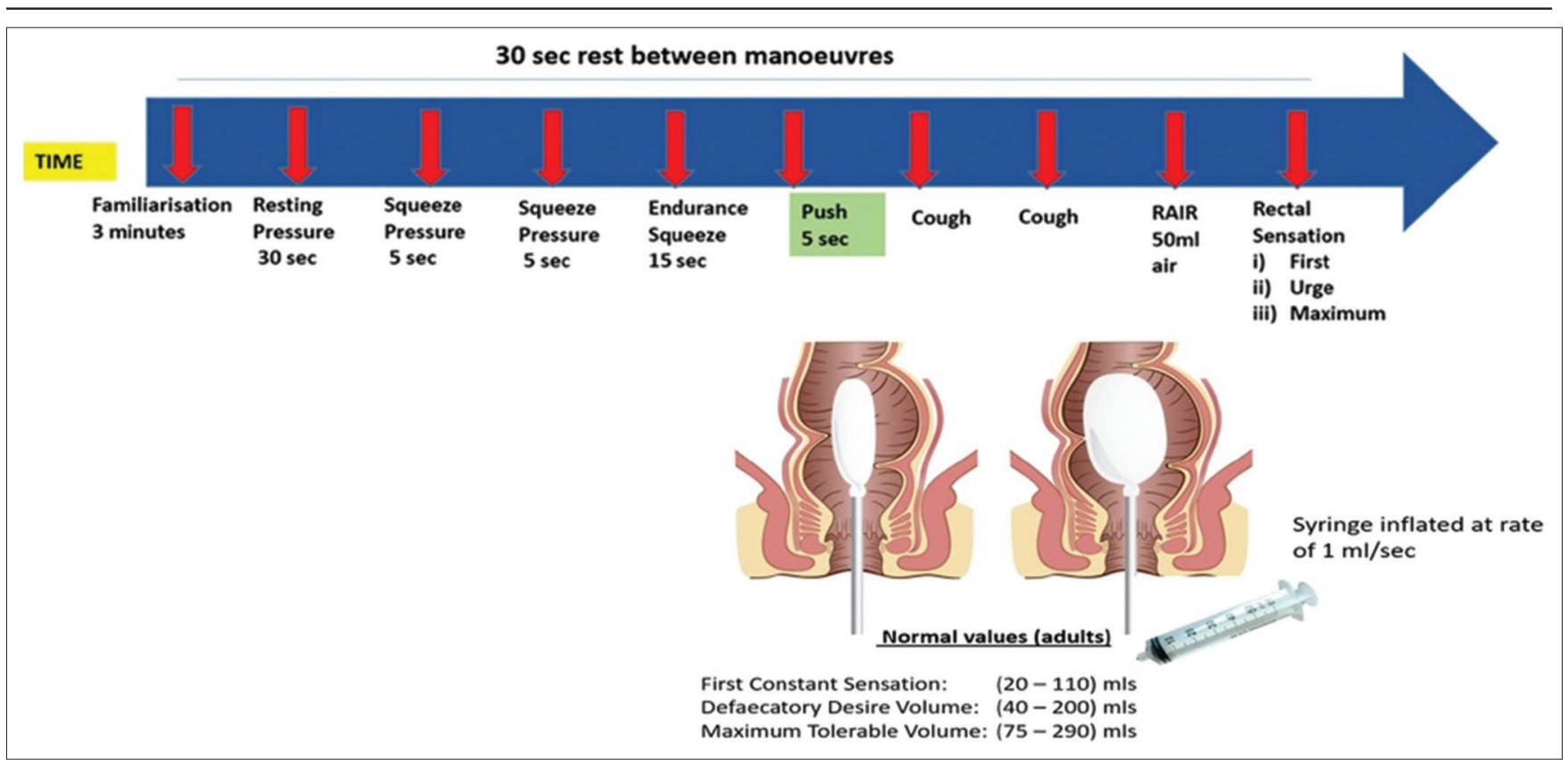

Figure 2: Awake high-resolution anorectal manometry protocol in kids (modified from adult practice for pediatric use) [2]

Table 1: Pediatric normal values for conventional ARM-based on sex and subdivides into-age- groups [1], [6]

\begin{tabular}{|c|c|c|c|c|c|c|c|c|c|c|c|c|c|c|c|c|}
\hline \multirow[t]{2}{*}{ Group variable } & \multicolumn{2}{|c|}{ Total } & \multicolumn{2}{|c|}{ Male } & \multicolumn{2}{|c|}{ Female } & \multirow{2}{*}{$p$-value } & \multicolumn{2}{|c|}{$<5$ year } & \multicolumn{2}{|c|}{ 5-8 year } & \multicolumn{2}{|c|}{ 9-12 year } & \multicolumn{2}{|c|}{$>12 y$} & \multirow{2}{*}{$\mathrm{p}$-value } \\
\hline & $\mathrm{n}$ & Mean $( \pm S D)$ & $n$ & Mean $( \pm$ SD $)$ & $\bar{n}$ & Mean $( \pm S D)$ & & $\mathrm{n}$ & Mean $( \pm$ SD) & $\bar{n}$ & Mean $( \pm$ SD) & $\mathrm{n}$ & Mean $( \pm S D)$ & $\mathrm{n}$ & Mean $( \pm$ SD) & \\
\hline $\begin{array}{l}\text { Maximum resting } \\
\text { pressure }(\mathrm{mm} \mathrm{Hg})\end{array}$ & 61 & $100(27)$ & 34 & $1110(23)$ & 27 & $110(18)$ & 0.950 & 9 & $115(28)$ & 19 & $104(20)$ & 19 & $112(17)$ & 14 & $110(22)$ & .490 \\
\hline $\begin{array}{l}\text { Mean resting } \\
\text { pressure }(\mathrm{mm} \mathrm{Hg})\end{array}$ & 61 & $83(23)$ & 34 & $92(19)$ & 27 & $92(16)$ & 0.860 & 9 & $94(24)$ & 19 & $86(15)$ & 19 & $94(15)$ & 14 & $96(19)$ & 0.290 \\
\hline $\begin{array}{l}\text { Maximum squeeze } \\
\text { pressure }(\mathrm{mm} \mathrm{Hg})\end{array}$ & 58 & 191 & 33 & 216 & 25 & $204(38)$ & .380 & 7 & $201(60)$ & 18 & 206 & 19 & $206(59)$ & 14 & $229(65)$ & 0.580 \\
\hline Length of HPZ $(\mathrm{cm})$ & 61 & $2.6(0.68)$ & 34 & $2.8(0.64)$ & 27 & $2.6(0.67)$ & 0.150 & 9 & $2.2(0.5)$ & 19 & $2.4(0.4)$ & 19 & $2.9(0.6)$ & 14 & $3.1(0.7)$ & 0.000 \\
\hline $\begin{array}{l}\text { Mechanical } \\
\text { resistance }(\mathrm{cm} \times \mathrm{mm} \mathrm{Hg})\end{array}$ & 61 & $219.4(87.14)$ & 34 & $256.2(79.32)$ & 27 & 238.1 (87.69) & 0.400 & 9 & $195.8(49.0)$ & 19 & $208.6(53.4)$ & 19 & $270.5(69.7)$ & 14 & $305.3(105.6)$ & 0.000 \\
\hline $\begin{array}{l}\text { Minimum rectal } \\
\text { compliance }\left(\mathrm{cm}^{3} / \mathrm{mm} \mathrm{Hg}\right)\end{array}$ & 60 & $-0.38(5.52)$ & 33 & $0.16(0.08)$ & 26 & $0.17(0.07)$ & 0.750 & 7 & $0.14(0.0)$ & 19 & $0.18(0.1)$ & 19 & $0.16(0.04)$ & 14 & $0.17(0.08)$ & 0.600 \\
\hline $\begin{array}{l}\text { Maximum rectal } \\
\text { compliance }\left(\mathrm{cm}^{3} / \mathrm{mm} \mathrm{Hg}\right)\end{array}$ & 60 & $-0.9(0.81)$ & 33 & $0.64(0.39)$ & 26 & $0.76(0.35)$ & 0.230 & 7 & $0.53(0.4)$ & 19 & $0.75(0.4)$ & 19 & $0.68(0.2)$ & 14 & $0.7(0.4)$ & 0.600 \\
\hline $\operatorname{RAIR}\left(\mathrm{cm}^{3}\right)$ & 61 & 15.7 & 34 & 12. & 27 & 15. & & 9 & & 19 & & 19 & & 14 & & 0.110 \\
\hline First sensation $\left(\mathrm{cm}^{3}\right)$ & 56 & $24.4(23.98)$ & 32 & $20.6(14.13)$ & 24 & $22.9(29.56)$ & 0.720 & 5 & $34(28.8)$ & 18 & $25(32.9)$ & 19 & $14.7(6.9)$ & 14 & $22.1(11.9)$ & 0.280 \\
\hline Urge $\left(\mathrm{cm}^{3}\right)$ & 56 & $45.9(34.55)$ & 32 & $39.7(28.11)$ & 24 & $43.3(37.03)$ & 0.670 & 5 & $36(27.0)$ & 18 & $37.2(35.9)$ & 19 & $36.3(19.8)$ & 14 & 55 (39.9) & 0.330 \\
\hline Discomfort $\left(\mathrm{cm}^{3}\right)$ & 56 & $91.6(50.17)$ & 32 & $81.6(46.9)$ & 24 & $102(54.59)$ & 0.190 & 5 & $48(22.8)$ & 18 & $75.8(45.3)$ & 19 & $88.2(45.0)$ & 14 & $127.1(53.7)$ & 0.000 \\
\hline
\end{tabular}

qualitative variables. When $p<0.05$, it was considered statistically significant.

\section{Ethical considerations}

The anonymity of all patients' data was preserved. Informed consent was not requested for the publication of this study because no personal data are mentioned.

\section{Results}

Out of 273 children included in our study, $68.5 \%$ were boys and $31.5 \%$ were girls (sex ratio $=2.2$ ). The mean age was 9 years ( 3 months -17 years old).

The most important indications were: CC, FI, or encopresis: 154 patients (56.4\%) had FI, 75 children
$(27.5 \%)$ had CC, and both indications were reported in 37 patients $(13.6 \%)$.

However, in 4 patients (1.5\%) aged more than 8 years, this test was used for the exploration of a pelvic floor dysfunction (rectal prolapse or Solitary Rectal Ulcer Syndrome) and in 1 infant presenting neonatal obstruction $(0.4 \%)$.

Seven patients had a history of sexual child abuse $(2.6 \%)$, seven patients had surgery for HD $(2.6 \%)$ and four patients had anorectal malformation (1.5\%). The majority of those children had a fecal incontinence or encopresis (94\%).

We performed 248 awake conventional ARM $(91 \%)$ and 25 under sedation (9\%).

The age of Children scheduled for ARM under sedation was between 3 months and 5 years. The indications of ARM were: CC (88\%), FI (8\%), and a neonatal obstruction (4\%). This test allowed the exclusion of HD in 21 children (84\%), 1 patient had 
Table 2: Clinical interpretation and indications of ARM/HRAM parameters [1]

\begin{tabular}{|c|c|c|}
\hline Parameter & Rationale & Outcome and clinical implications \\
\hline $\begin{array}{l}\text { Resting } \\
\text { pressure }\end{array}$ & $\begin{array}{l}\text { Assessment of } \\
\text { anal sphincter } \\
\text { baseline } \\
\text { integrity }\end{array}$ & $\begin{array}{l}\text { High: } \\
\text { Muscle spasm (voluntary or involuntary) } \\
\text { Functional contraction, for example, related to anxiety and } \\
\text { pain (such as in anal fissure) } \\
\text { Anal stenosis/stricture (should be assessed for by } \\
\text { gentle digital rectal examination preprocedure following } \\
\text { appropriate consent) } \\
\text { Low: } \\
\text { Weak/hypotensive anal sphincter } \\
\text { Idiopathic } \\
\text { Drug induced (sedation, anesthetic) } \\
\text { Injury (trauma, abuse) } \\
\text { Neurological (spinal cord disorder) }\end{array}$ \\
\hline $\begin{array}{l}\text { Squeeze } \\
\text { and } \\
\text { endurance } \\
\text { squeeze }\end{array}$ & $\begin{array}{l}\text { Assessment of } \\
\text { anal sphincter } \\
\text { contractile } \\
\text { integrity }\end{array}$ & $\begin{array}{l}\text { Low maximum pressure: } \\
\text { Non-compliant/poor understanding } \\
\text { Disorder of the anal sphincter (neurogenic or myogenic) } \\
\text { Injury } \\
\text { Reduced endurance pressure: } \\
\text { Non-compliant child/poor understanding } \\
\text { Nerve damage }\end{array}$ \\
\hline Push & $\begin{array}{l}\text { Assessment of } \\
\text { coordination (in } \\
\text { conjunction } \\
\text { with anal } \\
\text { sphincter } \\
\text { pressure) }\end{array}$ & $\begin{array}{l}\text { Adequate pressure with high ASP } \\
\text { Type } 1 \text { dyssynergia } \\
\text { Poor push with high ASP } \\
\text { Type } 2 \text { dyssynergia } \\
\text { Adequate pressure with no decrease in ASP } \\
\text { Type } 3 \text { dyssynergia } \\
\text { Poor push with no decrease in ASP } \\
\text { Type } 4 \text { dyssynergia }\end{array}$ \\
\hline Cough & $\begin{array}{l}\text { Assessment } \\
\text { of sacral reflex } \\
\text { arc }\end{array}$ & $\begin{array}{l}\text { Impaired response } \\
\text { Suggestive of damage to sacral reflex arc }\end{array}$ \\
\hline RAIR & $\begin{array}{l}\text { Functional } \\
\text { assessment } \\
\text { of presence of } \\
\text { endogenous } \\
\text { anorectal } \\
\text { neural network }\end{array}$ & $\begin{array}{l}\text { Positive RAIR: Excludes Hirschsprung's disease } \\
\text { Negative RAIR: } \\
\text { Possible Hirschsprung's disease (aganglionic rectal biopsy) } \\
\text { Anal sphincter achalasia (ganglionic rectal biopsy) } \\
\text { Partial RAIR has been suggested in anorectal inflammatory } \\
\text { conditions (e.g., allergy) }\end{array}$ \\
\hline $\begin{array}{l}\text { Rectal } \\
\text { sensation }\end{array}$ & $\begin{array}{l}\text { Assessment of } \\
\text { rectal sensation }\end{array}$ & $\begin{array}{l}\text { Help understand children' understanding of different } \\
\text { sensation generally marker for rectal capacity and } \\
\text { compliance, for example, in children with functional } \\
\text { constipation. } \\
\text { Impaired sensation may be seen in neurological } \\
\text { disturbances such as spinal cord disorders }\end{array}$ \\
\hline
\end{tabular}

an absent RAIR (4\%), and 4 results were inconclusive $(12 \%)$.

The awake ARM was performed on 4 patients with pelvic floor disorder and confirmed the presence of dyssynergy, while it was normal in 2 patients with chronic diarrhea and tenesmus.

To analyze the data of the other indications of awake ARM, we divided our patients into three groups: 152 children with FI (group 1), 53 with CC (group 2) and 37 with both of them (group 3). We analyzed and compared their parameters.

In group 1, ARM showed: 122 patients had abdominopelvic asynchrony (79.2\%), 38 had bad anal contraction $(24.7 \%)$, and 8 low RP $(5.2 \%)$. In group 2 , we have observed a dyssynergy in 32 patients $(60.4 \%)$, a megarectum in 6 children (11\%), and a RAIR absent suggesting HD (5\%) in 3 children.

In group 3 (children with $\mathrm{FI}+\mathrm{CC}$ ), 31 patients had a dyssynergy (83.7\%), 8 patients had a bad anal contraction $(21.6 \%)$, and 2 children had a megarectum $(5.4 \%)$.

The statistical analysis showed a significant difference in the age between the three groups (10.02 \pm 2.55 vs. $8.88 \pm 3.39$ vs. $9.23 \pm 2.55$ years; $p=0.022$ ) and limit signification for $\mathrm{RP}(8.38 \pm 3.86$ vs. $7.27 \pm 1.59$ vs. $7.39 \pm 1.56 \mathrm{mmHg} ; \mathrm{p}=0.050$ ) (Table 3).

Table 3: Values of awake ARM in children

\begin{tabular}{lllll}
\hline & $\mathrm{FI}$ & $\mathrm{CC}$ & $\mathrm{Fl}+\mathrm{CC}$ & $\mathrm{p}$ \\
\hline Age & $10.02 \pm 2.55$ & $8.88 \pm 3.39$ & $9.23 \pm 2.55$ & 0.022 \\
Resting pressure $(\mathrm{mmHg})$ & $8.38 \pm 3.86$ & $7.27 \pm 1.59$ & $7.39 \pm 1.56$ & 0.050 \\
Maximum pressure $(\mathrm{mmHg})$ & $16.05 \pm 8.33$ & $15.87 \pm 7.35$ & $15.59 \pm 9.57$ & 0.957 \\
Maximum tolerance $(\mathrm{ml})$ & $258.67 \pm 40.46$ & $257.63 \pm 48.40$ & $253.09 \pm 56.98$ & 0.808 \\
Number of dyssynergy & $122 / 152$ & $32 / 53$ & $31 / 37$ & 0.852 \\
\hline
\end{tabular}

Children with FI had a higher rate of dyssynergy, $80.2 \%$ and $83.8 \%$ in groups 1 and 3 , respectively, compared to $60.4 \%$ in patients with $C C(p=0.852)$. These patients have been referred for biofeedback therapy.

\section{Discussion}

On children, the physiopathology of $\mathrm{CC}$ with or without $\mathrm{FI}$ is multifactorial and complex with a limited scientific background. Understanding the involved pathophysiological and psychological mechanisms remains a challenging problem [2].

Gowers (1887) was the first to explain anorectal physiology [8]. Few years later, Denny-Brown and Robertson (1935) discovered the reflex of the internal anal sphincter relaxation in response to rectum distension [9].

More than a century has passed away since the development of ARM, actually considered as the gold standard exploration of anorectal function on adults and a very useful tool to guide management of bowel symptoms such as CC, fecal incontinence, and defecation disorders. Even if it is usually performed on adults, it has not been formally accepted as a regular diagnostic test on children, with very restricted data regarding indications, protocols used, and normal values [1]. It tests whether the kid can hold and pass stool correctly using his muscles and having normal sensation.

In the last few years, many advancements in ARM technology were seen, especially the highresolution (HRARM) and 3D high-definition manometry (HDARM) which replaced the conventional waterperfused systems [10] and became the gold-standard exploration of esophageal function.

Despite the benefits of using HRM, performing this test is still less enthusiastic for the assessment of anorectal function. We need a better understanding of the pathophysiology of defecation on children because during the test maneuvers (such as push, squeeze, and enhances squeeze) [11], [12], [13], [14], [15], the HRM can check the anorectum as a dynamic structure and so a higher appreciation of normal physiology.

On children, the ARM is usually performed under sedation [16], [17], either because of the young age, the 
significant child distress or anxiety, or learning difficulties or ARM is considered invasive by the parents [18].

Each center uses a different type of anesthesia such as ketamine, propofol, and preanesthetic such as midazolam and sometimes inhalation agents. The choice between these drugs depends on the center and on their influence in the assessment of the RIAR, although it has not been confirmed yet [19]. In this sense, several studies have been carried out: In 2014, Tram demonstrated that using propofol must be careful because it can reduce the RP and obscure cases of borderline anal achalasia [19].

Awake HRAM has many advantages, it provides more physiological parameters (sensory information and defecatory dynamic, Table 4) and it avoids especially the risks and the cost of GA [17], [20]. The child and parent can also interact and at the same time witness the type of defecatory problem. The involvement of parent and child may also have a positive impact on the outcome [2].

Table 4: Anorectal manometry parameters performed under sedation versus on awake kids [1]

\begin{tabular}{lll}
\hline & Under sedation & Awake \\
\hline Resting pressure & $\checkmark$ & $\checkmark$ \\
Squeeze pressure & & $\checkmark$ \\
Enhanced squeeze & & $\checkmark$ \\
Cough reflex & & $\checkmark$ \\
Push & $\checkmark$ & $\checkmark$ \\
Rectoanal inhibitory reflex & & $\checkmark$ \\
Rectal sensation & & $\checkmark$ \\
\hline
\end{tabular}

While ARM on awake has been commonly used on children with suspected Hirschsprung's disease [13], [21], the use of novel HRAM in this indication is still limited [1].

In comparison with suction rectal biopsy (SRB), a similar diagnostic accuracy was found with the ARM for the diagnosis of HD for children over 1 year old, with good sensitivity and specificity which were, respectively, $91 \%$ and $94 \%$. However, for infants (<1 year of age), the SRB is obligatory because error rate is around $26 \%$ making the ARM less reliable [10].

In general, an ARM is a good screening test for excluding HD. When founding a Functioning RAIR, the $H D$ is practically excluded and no need to do a RSB.

On the other hand, if RAIR is not found, a RSB is necessary to confirm the definitive diagnosis of HD. However, the use of ARM first reduces the need for RSB as well as its potential complications. The study published by Meinds in 2018 can be the start line toward a standardized method for assessment and measuring of anorectal reflexes in HD [22].

\section{Discussion of the ARM Results}

Little data are available concerning rectal function on children. A few studies have evaluated it on children with $\mathrm{FI}$ or $\mathrm{CC}$ because no abnormalities were described and these disorders were often related to psychological disturbances. However, in the last years, some studies have evaluated ARM on children and tried to understand defecation disorders mechanisms by analyzing the different parameters.

Eleni et al. have published in 2020 their experience with children presenting $\mathrm{CC}$ and $\mathrm{FI}$. The results of AHRAM were abnormal in 65 patients (58\%) (abnormal defined as at least one parameter to be impaired). Thirty-six sphincter dysfunction (32\%) was found: 26 low RP, 2 high RP, and 9 patients with RAIR absent. The sensation was analyzed only in awake kids: $22 \%$ hyposensitive rectum (20/91) and $21 \%$ hypersensitive rectum (19/91) [2].

In another study conducted by Voskuij et al., 88 patients were included: 69 with CC and 19 with FI. They compared their data with the data of 22 healthy volunteers without any gastrointestinal symptoms. The patients with retentive fecal incontinence (RFI) needed higher volumes to trigger the urge to defecate (100 \pm 50 $\mathrm{ml})$ compared to healthy volunteers $(82 \pm 38 \mathrm{ml})$ with $p<0.01$

The analysis of results did not find a significant difference between patients with $\mathrm{CC}$ and no incontinence, but a significant difference was reported between the three groups concerning the volume needed to reach the maximum tolerance of pain [23].

Another study by a Mexican team has evaluated the utility of the parameters done on ARM for children with RFI. A binomial logistic regression analysis was performed to assess the probability of $\mathrm{RFI}$, some parameters were evaluated in ARM: RP, first sensation, maximum tolerance of pain, and the presence or absence of dyssynergy.

The model had $67.6 \%$ accuracy and maximum tolerance of pain was the only evaluated variable that showed an influence in the mean comparison between the patients with functional constipation and the patients with RFI, statistically significant differences in the parameters of first sensation (66.50 \pm 7.54 vs. 105.70 $\pm 17.66 \mathrm{ml} ; \mathrm{p}=0.029)$ and maximum tolerance of pain $(131.43 \pm 63.97$ vs. $194.29 \pm 60.60 \mathrm{ml} ; p=0.006)$ were observed, respectively, (Tables 5) [24].

Table 5: Values of ARM in kids with retentive fecal incontinence and constipation [24]

\begin{tabular}{llll}
\hline & Constipation & Retentive fecal incontinence & $\mathrm{p}$ \\
\hline Resting pressure $(\mathrm{mmHg})$ & $41.29 \pm 16.31$ & $44.50 \pm 18.48$ & 0.602 \\
Maximum pressure $(\mathrm{mmHg})$ & $112.05 \pm 86.05$ & $121.64 \pm 59.20$ & 0.698 \\
First sensation $(\mathrm{ml})$ & $66.50 \pm 7.54$ & $105.70 \pm 17.66$ & 0.029 \\
Urgency $(\mathrm{ml})$ & $110.95 \pm 56.02$ & $154.21 \pm 67.12$ & 0.058 \\
Maximum tolerance $(\mathrm{ml})$ & $131.43 \pm 63.97$ & $194.29 \pm 60.60$ & 0.006 \\
\hline
\end{tabular}

Some type of dyssynergy was found: $47.6 \%$ on children with $\mathrm{CC}$ and $42.9 \%$ for those with $\mathrm{RFI}$ ( $p=0.52)[24]$.

In our study, the statistical analysis has found a significant difference in age between the three groups $(p=0.022)$ and a limit signification for $\operatorname{RP}(p=0.050)$. 
Children with FI had a higher rate of dyssynergy, $80.2 \%$ and $83.8 \%$ in groups 1 and 3 , respectively, compared to $60.4 \%$ in patients with CC $(p=0.852)$.

\section{Treatment of defecation disorders}

Each patient should receive a customized treatment taking into consideration his age, co-morbid conditions, underlying pathophysiology, patient's symptoms, patient's concerns, and expectations [5].

Many treatments can be prescribed according to the results of ARM. If dyssynergic defecation was found, a standard drug for constipation, biofeedback therapy, and other treatment such as botulinum toxin injection, ileostomy, or myectomy should be proposed [5].

ARM may help guide anal treatments, such as botulinum toxin injection, especially for children with hypertensive or poorly relaxing anal sphincter [25].

In our unit, we usually propose biofeedback therapy for children with dyssynergic defecation which was very beneficial.

Nowadays, the ARM is widely available. It became more performed in pediatric population to diagnose motility disorders. The improvements of technology are now making ARM more informative and much easier to perform. However, we still need more prospective studies to evaluate the impact of this test on medical and surgical treatment and long-term outcome [18].

One of the solutions to improve the treatment of defecation disorders on children is to use scientific evidence with a multidisciplinary team. For this purpose, The Children's Anorectal Physiology Service (CAPS) was proposed in September 2016; many tests included: HRAM, complimentary tests (endoanal ultrasound and transit marker studies), psychological, and bowel assessments [2]. They concluded that scientific investigations combined with multidisciplinary team can reduce patient self-report illness severity and improve patient satisfaction. To resolve a complex problem, we need a scientific solution.

In conclusion, AMR is the gold standard to explore defecation disorders in adults, it has also been evaluated on children in a few studies and remains the first choice investigation in the context of fecal incontinence and CC. In our study, we found a higher rate of dyssynergy on children with FI $(80 \%)$, they have been referred for biofeedback therapy. We have also been able to exclude HD in infants with CC even if it was performed under sedation.

However, more prospective, controlled, and multicenter studies should be conducted to assess the impact of ARM on the treatment and the long-term outcomes. The development of centers like "CAPE" with new technologies should be proposed to optimize the performance of manometry on children, so ARM can become the most performed motility study in pediatric population.

\section{References}

1. Athanasakos E, Cleeve S, Thapar N, Lindley K, Perring S, Cronin $\mathrm{H}$, et al. Anorectal manometry in children with defecation disorders BSPGHAN motility working group consensus statement. Neurogastroenterol Motil. 2020;32(6):1-11. https:// doi.org/10.1111/nmo.13797

2. Athanasakos E, Dalton S, McDowell S, Shea T, Blakeley K, Rawat D, et al. Scientific solution to a complex problem: Physiology and multidisciplinary team improve understanding and outcome in chronic constipation and faecal incontinence. Pediatr Surg Int. 2020;36(3):295-303. https://doi.org/10.1007/ s00383-019-04605-y

PMid:31844977

3. Remes-Troche JM, Rao SS. Diagnostic testing in patients with chronic constipation. Curr Gastroenterol Rep. 2006;8(5):41624. https://doi.org/10.1007/s11894-006-0028-2 PMid:16968610

4. Rao SS, Ozturk R, Laine L. Clinical utility of diagnostic tests for constipation in adults: A systematic review. Am J Gastroenterol. 2005;100(7):1605-15. https://doi. org/10.1111/j.1572-0241.2005.41845.x

PMid:15984989

5. Rao SS, Patcharatrakul T. Diagnosis and treatment of dyssynergic defecation. J Neurogastroenterol Motil. 2016;22(3):423-35. https://doi.org/10.5056/jnm16060 PMid:27270989

6. Banasiuk M, Banaszkiewicz A, Dziekiewicz M, Załęski A, Albrecht P. Values from three-dimensional high-resolution anorectal manometry analysis of children without lower gastrointestinal symptoms. Clin Gastroenterol Hepatol. 2016;14(7):993-1000.e3. https://doi.org/10.1016/j. cgh.2016.01.008

PMid:26820403

7. Azpiroz F, Enck P, Whitehead WE. Anorectal functional testing: Review of collective experience. Am J Gastroenterol. 2002;97(2):232-40. https://doi. org/10.1111/j.1572-0241.2002.05450.x PMid:11866256

8. Gowers WR $4^{\text {th }}$. The automatic action of the sphincter ani. Proc $R$ Soc London. 1878;26(179-184):77-84. https://doi.org/10.1098/ rspl.1877.0013

9. Denny-Brown D, Robertson EG. An investigation of the nebvous conteol of defecation. Brain. 1935;58(2):256-310.

10. Tambucci R, Quitadamo P, Thapar N, Zenzeri L, Caldaro T, Staiano A, et al. Diagnostic tests in pediatric constipation. J Pediatr Gastroenterol Nutr. 2018;66(4):e89-98. https://doi. org/10.1097/mpg.0000000000001874

PMid:29287015

11. Ratuapli SK, Bharucha AE, Noelting J, Harvey DM, Zinsmeister AR. Phenotypic identification and classification of functional defecatory disorders using high-resolution anorectal manometry. Gastroenterology. 2013;144(2):314-22.e2. https:// doi.org/10.1053/j.gastro.2012.10.049

PMid:23142135 
12. Carrington E V., Brokjær A, Craven H, Zarate N, Horrocks EJ, Palit $\mathrm{S}$, et al. Traditional measures of normal anal sphincter function using high-resolution anorectal manometry (HRAM) in 115 healthy volunteers. Neurogastroenterol Motil. 2014;26(5):625-35. https://doi.org/10.1111/nmo.12307 PMid:24628873

13. Tang YF, Chen JG, An HJ, Jin P, Yang L, Dai ZF, et al. Highresolution anorectal manometry in newborns: Normative values and diagnostic utility in Hirschsprung disease. Neurogastroenterol Motil. 2014;26(11):1565-72. https://doi. org/10.1111/nmo.12423 PMid:25263969

14. Wu JF, Lu CH, Yang CH, Tsai IJ. Diagnostic role of anal sphincter relaxation integral in high-resolution anorectal manometry for hirschsprung disease in infants. J Pediatr. 2018;194:136-41.e2. https://doi.org/10.1016/j.jpeds.2017.10.017

PMid:29212617

15. Benninga MA, Voskuijl WP, Akkerhuis GW, Taminiau JA, Büller HA. Colonic transit times and behaviour profiles in children with defecation disorders. Arch Dis Child. 2004;89(1):13-6. PMid:14709493

16. Keshtgar AS, Athanasakos E, Clayden GS, Ward HC. Evaluation of outcome of anorectal anomaly in childhood: The role of anorectal manometry and endosonography. Pediatr Surg Int. 2008;24(8):885-92. https://doi.org/10.1007/s00383-008-2181-1 PMid:18512062

17. Keshtgar AS, Choudhry MS, Kufeji D, Ward HC, Clayden GS Anorectal manometry with and without ketamine for evaluation of defecation disorders in children. J Pediatr Surg. 2015;50(3):43843. https://doi.org/10.1016/j.jpedsurg.2014.08.016 PMid:25746704

18. Rodriguez L, Sood M, Di Lorenzo C, Saps M. An ANMSNASPGHAN consensus document on anorectal and colonic manometry in children. Neurogastroenterol Motil. 2017;29(1):18. https://doi.org/10.1111/nmo.12944 PMid:27723185

19. Tran K, Kuo B, Zibaitis A, Bhattacharya $S$ Cote C, Belkind-Gerson J. Effect of propofol on anal sphincter pressure during anorectal manometry. J Pediatr Gastroenterol Nutr. 2014;58(4):495-7. https://doi.org/10.1097/ mpg.0000000000000190

PMid:24121151

20. Keshtgar AS, Ward HC, Clayden GS. Pathophysiology of chronic childhood constipation: Functional and morphological evaluation by anorectal manometry and endosonography and colonic transit study. J Pediatr Surg. 2013;48(4):806-12. https:// doi.org/10.1016/j.jpedsurg.2012.08.037

PMid:23583138

21. Ambartsumyan L, Rodriguez L, Morera C, Nurko S. Longitudinal and radial characteristics of intra-anal pressures in children using 3D high-definition anorectal manometry: New observations. Am J Gastroenterol. 2013;108(12):1918-28. https://doi.org/10.1038/ ajg.2013.361

PMid:24169274

22. Meinds RJ, Trzpis M, Broens PM. Anorectal manometry may reduce the number of rectal suction biopsy procedures needed to diagnose hirschsprung disease. J Pediatr Gastroenterol Nutr. 2018;67(3):322-7. https://doi.org/10.1097/ mpg.0000000000002000

PMid:29652729

23. Voskuijl WP, Van Ginkel R, Benninga MA, Hart GA, Taminiau JA, Boeckxstaens GE. New insight into rectal function in pediatric defecation disorders: Disturbed rectal compliance is an essential mechanism in pediatric constipation. J Pediatr. 2006;148(1):627. https://doi.org/10.1016/j.jpeds.2005.08.061 PMid:16423599

24. Toro-Monjaraz EM, Peña-Vélez R, Ignorosa-Arellano KR, Zaráte-Mondragón F, Cervantes-Bustamante R, RamírezMayans JA. Anorectal manometry in children with retentive fecal incontinence: What parameters should we evaluate? Rev Gastroenterol Méx. 2019;84(3):419-22. https://doi. org/10.1016/j.rgmxen.2019.02.012 PMid:31151864

25. Koivusalo Al, Pakarinen MP, Rintala RJ. Botox injection treatment for anal outlet obstruction in patients with internal anal sphincter achalasia and Hirschsprung's disease. Pediatr Surg Int. 2009;25(10):873-6. https://doi.org/10.1007/ s00383-009-2438-3

PMid:19662428 